\title{
DEFINIÇÃO DE PRAZO DE VALIDADE E REVALIDAÇÃO DE PRODUTOS QUÍMICOS
}

\author{
L.R. ORIQUI ${ }^{1}$, M. MORI ${ }^{2}$ e P. WONGTSCHOWSKI ${ }^{3}$ \\ ${ }^{1}$ Universidade Estadual de Campinas, Faculdade de Engenharia Química \\ ${ }^{2}$ Universidade Estadual de Campinas, Faculdade de Engenharia Química \\ ${ }^{3}$ Executivo do Setor Químico - Grupo Ultra \\ E-mail para contato: luoriqui@uol.com.br
}

\begin{abstract}
RESUMO - A indústria química, ciente de sua responsabilidade ambiental, vem buscando alternativas que contribuam na busca pelo equilíbrio, principalmente com pesquisas no âmbito de estudos de estabilidade, que possibilitem o estabelecimento seguro de prazo de validade e revalidação de seus produtos, de tal forma a minimizar o impacto ambiental resultante do descarte de produtos teoricamente vencidos, mas ainda íntegros em suas especificações. A Universidade Estadual de Campinas, desde 2008 trabalha com pesquisas sobre revalidação, em uma parceria universidade-empresa e, posteriormente, também do Conselho Nacional de Desenvolvimento Científico e Tecnológico, CNPq. Os esforços simultâneos resultaram na pesquisa/desenvolvimento de uma nova metodologia, contundente na definição de prazo de validade e que possibilita revalidação de produtos químicos, viabilizando, em determinadas situações, a revalidação sem abertura da embalagem final do produto.
\end{abstract}

\section{INTRODUÇÃO}

O tema sustentabilidade é amplamente discutido e cada vez mais priorizado em todos os continentes. O planeta Terra urge por medidas imediatas que minimizem o impacto ambiental resultante de gestões inadequadas de diversas vertentes, entre elas, o uso irresponsável de produtos até seu descarte muitas vezes não apropriado. 
A indústria química, ciente de sua responsabilidade ambiental, vem buscando alternativas que contribuam na busca pelo equilíbrio, principalmente com pesquisas no âmbito de estudos de estabilidade, que possibilitem o estabelecimento seguro de prazo de validade e revalidação de seus produtos.

No Brasil, devido a Lei do Código do Consumidor, Lei 8078 de 11 de setembro de 1990, que estabelece que todo produto comercializado precisa conter o prazo de validade em seu rótulo, os estudos sobre possibilidade de revalidação desse prazo, quando o produto estiver seguramente em condição de uso, vem tomando cada vez mais vulto. Fóruns para discussão do tema, envolvendo indústrias, associações de classes, pesquisadores, universidades, escritórios de advocacia e órgãos governamentais já são uma realidade.

A Universidade Estadual de Campinas, desde 2008 trabalha com pesquisas sobre revalidação, com o apoio da indústria Oxiteno S.A. e, posteriormente, também do CNPq, e das empresas Nanotimize Tecnologia e Arysta LifeScience do Brasil Indústria Química e Agropecuária Ltda. Os esforços simultâneos resultaram no desenvolvimento/pesquisa de uma nova metodologia, contundente na definição de prazo de validade e que viabiliza revalidação de produtos químicos, possibilitando, em determinadas situações, a revalidação sem abertura da embalagem final do produto.

A indicação de prazo de validade nos produtos é também um respaldo para os fabricantes em relação à sua co-responsabilidade, na medida em que condiciona o prazo à condições de armazenamento indicadas no rótulo - ou nota fiscal do produto, quando estes são comercializados a granel.

A quimiometria é o alicerce de uma nova metodologia que está sendo desenvolvida para revalidação de produtos químicos. Nela, o "Mapa Quimiométrico do Produto" será o indicador da possibilidade de revalidação e do prazo recomendado.

O transporte seguro de produtos químicos também é uma preocupação de toda indústria bem como de ambientalistas. Uma vez possibilitada a revalidação, haverá impacto positivo em termos de logística reversa através da minimização do retorno e descarte de produtos.

\subsection{Legislações sobre Prazo de Validade para Produtos Químicos}

Não há legislação internacional específica para produtos químicos no que tange a estudos de estabilidade e definição de prazos de validade, cabendo a cada empresa a administração segura a respeito da garantia de qualidade de seus produtos, respaldadas pelas políticas de Boas Práticas de Fabricação praticadas em seus países de origem.

As legislações internacionais vigentes sobre prazos de validade tratam preponderantemente sobre medicamentos, cosméticos e produtos alimentícios e, 
consequentemente, são nelas que a indústria química nacional se baseia para definir os prazos de seus produtos.

No Brasil, o segmento químico contesta seu enquadramento na Lei do Código Consumidor - Lei ${ }^{\circ}$ 8.078, de 11 de setembro de 1990, ou Código de Defesa do Consumidor - CDC, atestando estar sob a égide do Código Civil, quando seus produtos são utilizados como matéria prima, ou insumo, no fabrico de outros produtos, ou seja, quando são comercializados no mercado business to business, B2B. Somente quando comercializados como produto final, estariam enquadrados no CDC.

A base para esta contestação está relacionada com os conceitos de consumidor e destinatário final. A lei 8.078/1990, no Art. $2^{\circ}$, define consumidor como sendo "toda pessoa física ou jurídica que adquire ou utiliza produto ou produto como destinatário final”, porém destinatário final de um produto ou serviço é entendido como aquele que os adquire para atendimento de sua necessidade própria e não para uso em sua atividade empresarial, ou fim profissional. Sob esta perspectiva, as pessoas jurídicas podem ser entendidas como destinatárias finais quando adquirem bens de consumo, mas não quando adquirem bens de capital para sua atividade empresarial ou atividade intermediária de um ciclo de produção (MPF, 2011).

\subsection{Legislação Nacional}

A seguir serão apresentadas algumas legislações que tratam sobre prazo de validade.

Como se observa, elas não contemplam a restrição à revisão do prazo de validade antes desse se expirar. Isso se deve, principalmente, ao fato de, para produtos regulados pela Agência Nacional de Vigilância Sanitária, ANVISA, ser exigido para registro do produto, a atribuição de prazo de validade, determinado por estudos de estabilidade. Com o prazo já registrado, não caberia revalidação, mesmo antes de seu vencimento, já que isso incorreria em prazo superior ao autorizado.

No caso da indústria química, apesar de no Brasil ela atualmente ainda ser considerada enquadrada na Lei do Código do Consumidor, independentemente da comercialização final de seus produtos, e, portanto, com a obrigatoriedade de constar prazo de validade em seus rótulos, ela não é regulamentada por agências que estipulem a necessidade de estudos de estabilidade para definição do prazo e nem registro desses.

Nesse caso específico, seria possível então se pensar em revalidação desde que devidamente respaldada por estudos que assegurem sua estabilidade pelo novo prazo.

Como não há legislação para estudos de estabilidade no segmento químico, serão discutidos os principais textos que tratam sobre prazo de validade em segmentos 
regulamentados, como os das indústrias farmacêutica, de produtos saneantes e de higiene pessoal, cosméticos e perfumes.

\subsubsection{Lei $\mathbf{n}^{0} 6.360$, de 23 de setembro de 1976}

A Lei 6.360/76 dispõe sobre a vigilância sanitária a que estão sujeitos os medicamentos, as drogas, os insumos farmacêuticos e correlatos, cosméticos, saneantes e outros produtos.

\subsubsection{Lei $\mathrm{n}^{0}$ 6.437, de 20 de agosto de 1977}

A Lei 6437/77 configura as infrações à legislação sanitária federal, estabelece sanções respectivas e dá outras providências.

Em seu artigo 10, inciso XVIII, diz que são infrações sanitárias "importar ou exportar, expor à venda ou entregar ao consumo produtos de interesse à saúde cujo prazo de validade tenha se expirado, ou apor-lhes novas datas, após expirado o prazo".

A Medida Provisória $\mathrm{N}^{\mathrm{o}} 2.190-34$, de 23 de agosto de 2001, que altera dispositivos das Leis $\mathrm{n}^{\mathrm{O}}$ 9.782, de 26 de janeiro de 1999, e $\mathrm{n}^{\mathrm{o}}$ 6.437, de 20 de agosto de 1977, em seu artigo 12, inciso XVIII, corrobora com o texto da Lei $n^{\circ} 6.437 / 77$, no que tange a infrações sanitárias para produtos comercializados com prazo de validade vencido, ou revalidados após esse prazo.

\subsubsection{Lei $\mathbf{n}^{0} 9.782$, de 26 de janeiro de 1999}

Define o Sistema Nacional de Vigilância Sanitária, cria a Agência Nacional de Vigilância Sanitária, ANVISA, e dá outras providências.

\subsubsection{Resolução - RDC n $\mathbf{n}^{0} 210$, de 04 de agosto de 2003}

A RDC 210/2003, regulamenta sobre as Boas Práticas de Fabricação de Medicamentos e define Certificado de Registro do Produto como um documento legal emitido pela Autoridade Sanitária competente, no qual consta a formulação qualitativa e quantitativa do produto, incluindo detalhes sobre embalagem, rotulagem e prazo de validade. Determina também que Boas Práticas de Fabricação é a parte da Garantia da Qualidade que assegura que os produtos são consistentemente produzidos e controlados, com padrões de qualidade apropriados para o uso pretendido e requerido pelo registro.

No item 13.6.2, é determinado que o reprocessamento de produtos reprovados pelo controle de qualidade, somente pode ser permitido se a qualidade do produto terminado não for afetada, se as especificações forem atendidas e se a operação for realizada de acordo com procedimentos autorizados e definidos após a avaliação dos riscos envolvidos. 
A definição anterior trata de produtos reprovados pelo controle de qualidade e não produtos com prazo expirado. Também remete a reprocessamento e não a revalidação.

A revalidação, tratada no item 19.4.4, refere-se essencialmente ao processo do produto e não a seu prazo de validade.

\subsubsection{Resolução - RDC no 17 , de 16 de abril de 2010}

A RDC 17/2010, que atualiza e substitui a RDC 210/2003, traz duas definições relevantes em seu artigo $5^{\circ}$, incisos XV e XVI:

Inciso XV: data de validade é a data estabelecida nas embalagens de medicamentos (usualmente em rótulos) até a qual se espera que o produto permaneça dentro das especificações, desde que armazenado corretamente. Essa data é estabelecida por lote, somando-se o prazo de validade à data de fabricação.

Inciso XVI: data de reteste é a data estabelecida pelo fabricante do insumo, baseada em estudos de estabilidade, após a qual o material deve ser reanalisado para garantir que ainda está adequado para uso imediato, conforme testes indicativos de estabilidade definidos pelo fabricante do insumo e mantidas as condições de armazenamento pré-estabelecidas. A data de reteste somente é aplicável quando o prazo de validade não foi estabelecido pelo fabricante de insumo.

\subsubsection{Decreto 8077, de 14 de agosto de 2013}

Regulamenta as condições para o funcionamento de empresas sujeitas ao licenciamento sanitário, e o registro, controle e monitoramento, no âmbito da vigilância sanitária, dos produtos de que trata a Lei $n^{0}$ 6.360, de 23 de setembro de 1976, e dá outras providências.

\subsubsection{Resolução - RDC no 47, de 25 de outubro de 2013}

A Resolução 47/2013 aprova o Regulamento Técnico de Boas Práticas de Fabricação para Produtos Saneantes e dá outras providências.

O item 15.22 define que as etiquetas ou sistemas de informações, devem disponibilizar, entre outras, a data de validade do produto.

O item 15.24 define que deve ser respeitado o prazo de validade estabelecido pelo fabricante das matérias primas e que a reanálise dessas, em estoque, serve apenas para confirmação da manutenção de suas especificações e não pode ser usada para estender o prazo de validade. 
O item 15.24 inviabiliza, portanto, revalidação feita pela empresa usuária da matéria prima. Essa restrição está de acordo com a metodologia de revalidação de produtos químicos, em desenvolvimento, que restringe a revalidação ao fabricante do produto, detentor dos estudos de estabilidade específicos e essenciais para esse fim.

\subsubsection{Resolução - RDC n⿳ 48 , de 25 de outubro de 2013}

A Resolução 48/2013 aprova o Regulamento Técnico de Boas Práticas de Fabricação para Produtos de Higiene Pessoal, Cosméticos e Perfumes, e dá outras providências.

O item 18.24.2 define que somente as matérias primas liberadas pelo controle de qualidade e que estejam dentro dos respectivos prazos de validade devem ser utilizadas.

Novamente, o texto está de acordo com a metodologia de revalidação de produtos químicos, em desenvolvimento, pois ela adota como premissa a revalidação de produtos com prazo de validade ainda não expirado.

Em relação às perguntas mais frequentes referentes à RDC 48/2013 (ANVISA, 2012), o ítem 1.12 trata especificamente sobre revalidação de matéria prima e responde que não é permitida a revalidação de matérias primas de cosméticos, saneantes e produtos para a saúde, mas, ainda na mesma resposta, dá continuidade informando que insumos fora do prazo de validade deverão ser, obrigatoriamente, descartados ou encaminhados à correta forma de descarte. Ou seja, pode-se concluir que a revalidação não permitida refere-se a produtos já vencidos.

\subsection{Legislação Internacional}

Como já discutido, não há legislação específica para estudos de estabilidade e definição de prazos de validade para produtos químicos no mercado internacional, justamente por não haver a exigência de identificação desse prazo para esse segmento específico.

No entanto, como referência, o Departamento de Defesa dos Estados Unidos, ou simplesmente DoD, e a agência Food and Drug Administration, FDA, definem dois tipos de códigos para prazo de validade para medicamentos (DoD, 2003):

- Tipo I: itens com datas de expiração de validade, a partir da qual o material é considerado impróprio para uso;

- Tipo II: itens que podem ter seu prazo estendido através de inspeções visuais e/ou testes de laboratórios, conforme exigido por suas normas aplicáveis de gestão.

Nos Estados Unidos, o programa de extensão do prazo de validade, shelf-life extension program - SLEP, conduzido por uma parceria entre o DoD e a agência FDA, já trabalha com 
o conceito de revalidação de medicamentos, desde que atendidas determinadas especificações, garantidas por testes laboratoriais por eles indicados/conduzidos (Khan et al, 2014).

Por meio de numerosas pesquisas regulamentares e por pesquisas científicas contundentes no âmbito farmacêutico, que incluíram estudos de estabilidade e vários testes físicos e químicos, obteve-se um banco de dados que possibilitou recursos científicos para compreensão e identificação de falhas nos testes operacionais, propiciando o desenvolvimento de novas formulações ou embalagens mais robustas (Khan et al, 2014).

\section{ESTUDOS DE ESTABILIDADE E PRAZOS DE VALIDADE}

Segundo a Portaria $\mathrm{N}^{0}$ 500/MS/SNVS, de 09 de outubro de 1997, "estabilidade é a capacidade de um produto de manter suas características originais conforme suas especificações de pureza, qualidade e potência".

Já na Resolução RDC N ${ }^{0}$ 157/2002, define prazo de validade como "tempo durante o qual o produto poderá ser usado, caracterizado como período de vida útil e fundamentado nos estudos de estabilidade específicos" e estabilidade como a "capacidade de um produto manter inalteráveis suas propriedades e seu desempenho durante um tempo definido, de acordo com as condições previamente estabelecidas, relacionadas à sua identidade, concentração ou potência, qualidade, pureza e aparência física".

A indústria química vem se inspirando nas práticas já estabelecidas da indústria farmacêutica e em sua experiência nacional e internacional, para direcionamento de seus estudos de estabilidade. Oriqui et al (2014) criaram um Guia de estabilidade específico para produtos químicos, amparando-se nos parâmetros já globalmente aceitos para o segmento farmacêutico, enquanto investem em pesquisas laboratoriais para definição de parâmetros específicos para a indústria química.

\subsection{Prazo de Validade}

A correta definição do prazo de validade de um produto impacta diretamente tanto em seu mercado quanto no meio ambiente. Se subestimado, restringe sua comercialização e estocagem; já se superestimado, pode pôr em risco sua eficiência ou até mesmo a saúde e segurança do consumidor. Por sua vez, o descarte prematuro de produtos que mantém garantidas suas especificações de qualidade, resultam em forte impacto ao meio ambiente.

A padronização de metodologia para estudos de estabilidade para a indústria química é essencial para o estabelecimento adequado de prazos de validade para seus produtos e, posteriormente, para possível revalidação desses. 
É necessário que parâmetros, definições, planejamento e controles fundamentais sejam corretamente entendidos e absorvidos para implantação eficaz desses estudos.

\subsection{Data de Reteste $x$ Revalidação}

Essa diferenciação é essencial para o entendimento dos mecanismos da nova metodologia de revalidação, em desenvolvimento, e para o correto enquadramento das expectativas da indústria em relação à atribuição de uma data limite de validade para seus produtos.

Data de Reteste: segundo definição do Art. $5^{\circ}$ da Resolução RDC 17/2010 e as perguntas e respostas sobre ele (ANVISA, 2010), a data de reteste somente é aplicável quando o prazo de validade não foi estabelecido pelo fabricante do insumo. Observar que a data de reteste garante o uso "imediato" do produto/insumo e desde que não tenha sido anteriormente atribuído a ele prazo de validade. Caso o insumo seja utilizado novamente em uma ocasião posterior, deve ser submetido a outro reteste antes do uso.

Revalidação: novo prazo de validade atribuído ao produto após testes analíticos específicos validados por meio de estudos de estabilidade conduzidos antes de seu vencimento, e que garantam sua adequabilidade para uso durante o novo prazo proposto. $\mathrm{O}$ conhecimento da rota de degradação do produto e os possíveis produtos degradantes formados, são essenciais para garantia segura do novo prazo. Esse conhecimento contundente é possível com a associação dos estudos de estabilidade, quimiometria, análises químicas convencionais e análises espectrométricas.

O fluxograma a seguir, figura 1 , foi construído considerando como premissa o não enquadramento da indústria química na Lei do Código Consumidor quando seus produtos forem direcionados ao mercado Business to Business, B2B, ou seja, quando forem insumos em novos processos produtivos. Caso a premissa não seja atendida, considerar somente prazo de validade, tanto para o mercado B2B, quanto para o Business to Consumer, B2C.

Aos produtos direcionados ao mercado, B2B, poderiam ser atribuídos tanto prazo de reteste quanto prazo de validade, cabendo ao fabricante as análises econômica e técnica da definição. Já aos produtos direcionados ao mercado B2C, só é possível a atribuição de prazo de validade. 




Figura 1 - Reteste ou Revalidação?

\subsection{QUIMIOMETRIA}

Segundo Varmuza e Filzmoser (2009), quimiometria é um disciplina que utiliza métodos estatísticos e matemáticos, para planejar e/ou obter otimização de procedimentos e experimentos, objetivando a extração do maior número possível de informações químicas relevantes através da análise química de dados. Os autores exemplificam os típicos usos da quimiometria:

- Determinação da concentração de um composto em uma mistura complexa

- Classificação das origens das amostras

- Predição de propriedade o atividades de um composto químico

- Reconhecimento da presença/ausência de subestruturas na estrutura química de um composto orgânico desconhecido

- Avaliação do estado de um processo na tecnologia química

Os estudos de estabilidade em condições de estresse são particularmente fundamentais para o conhecimento da rota de degradação de um produto e é este conhecimento, associado às análises quimiométricas dos espectros e análises químicas convencionais em todos os 
parâmetros dos estudos de estabilidade, que estruturam o desenvolvimento da nova metodologia de revalidação para produtos químicos.

\section{METODOLOGIA PARA REVALIDAÇÃO DE PRODUTOS QUÍMICOS}

O foco da metodologia, já em fase de validação por meio de testes laboratoriais, e que será denominada simplesmente por metodologia "ChemoMap", é direcionado a produtos para os quais foram atribuídos prazo de validade e não prazo de reteste.

Ressalta-se que a extensão do prazo está vinculada à forma como o produto foi armazenado e não só especificamente à análise do lote ao qual ele pertence.

Na fase inicial da metodologia, são feitas análises multivariadas em base de dados já existentes para, além de indicar as variáveis críticas a serem monitoradas, estabelecer qual a técnica espectrofotométrica de infravermelho mais adequada para o produto em análise. $\mathrm{O}$ tipo de embalagem de comercialização interfere nessa indicação e, portanto, é importante que as análises sejam conduzidas em produtos em suas embalagens originais ou mimetizadas.

Principais indicações de espectrofotometria de infravermelho para análise de processos (Trevisan e Poppi, 2006):

- Espectroscopia no infravermelho próximo (Near Infrared Spectroscopy, NIR): compreende a faixa espectral 780 a $2.500 \mathrm{~nm}$. Bastante utilizado para controle de matérias primas em processos de manufatura. Baixo custo do equipamento em relação à espectroscopia no infravermelho médio.

- Espectroscopia no infravermelho médio (Medium Infrared Spectroscopy, MIR): compreende a faixa espectral 2.500 a $5.000 \mathrm{~nm}$. Inicialmente, era principalmente utilizada em sistemas multicomponentes devido às sobreposições espectrais, porém com a utilização conjunta de métodos matemáticos de análise multivariada, quimiometria, determinações simultâneas em sistemas complexos puderam ser desenvolvidas.

- Espectroscopia Raman: utiliza o espalhamento inelástico da luz para analisar os modos de vibração e rotação das moléculas. Tem apresentado forte desenvolvimento nos últimos anos devido à eficiência de fibras óticas na região visível e NIR, onde lasers pequenos, portáteis e refrigerados podem ser utilizados para a coleta dos dados espectroscópicos.

A faixa do infravermelho próximo NIR, imediatamente além da faixa de comprimento de onda visível, é especialmente importante para aplicações práticas por causa da profundidade 
de penetração muito maior da radiação NIR na amostra comparada à espectroscopia de infravermelho médio.

A Figura 2, a seguir, apresenta de maneira sintetizada, a estrutura de desenvolvimento da metodologia de revalidação ChemoMap, para produtos químicos.

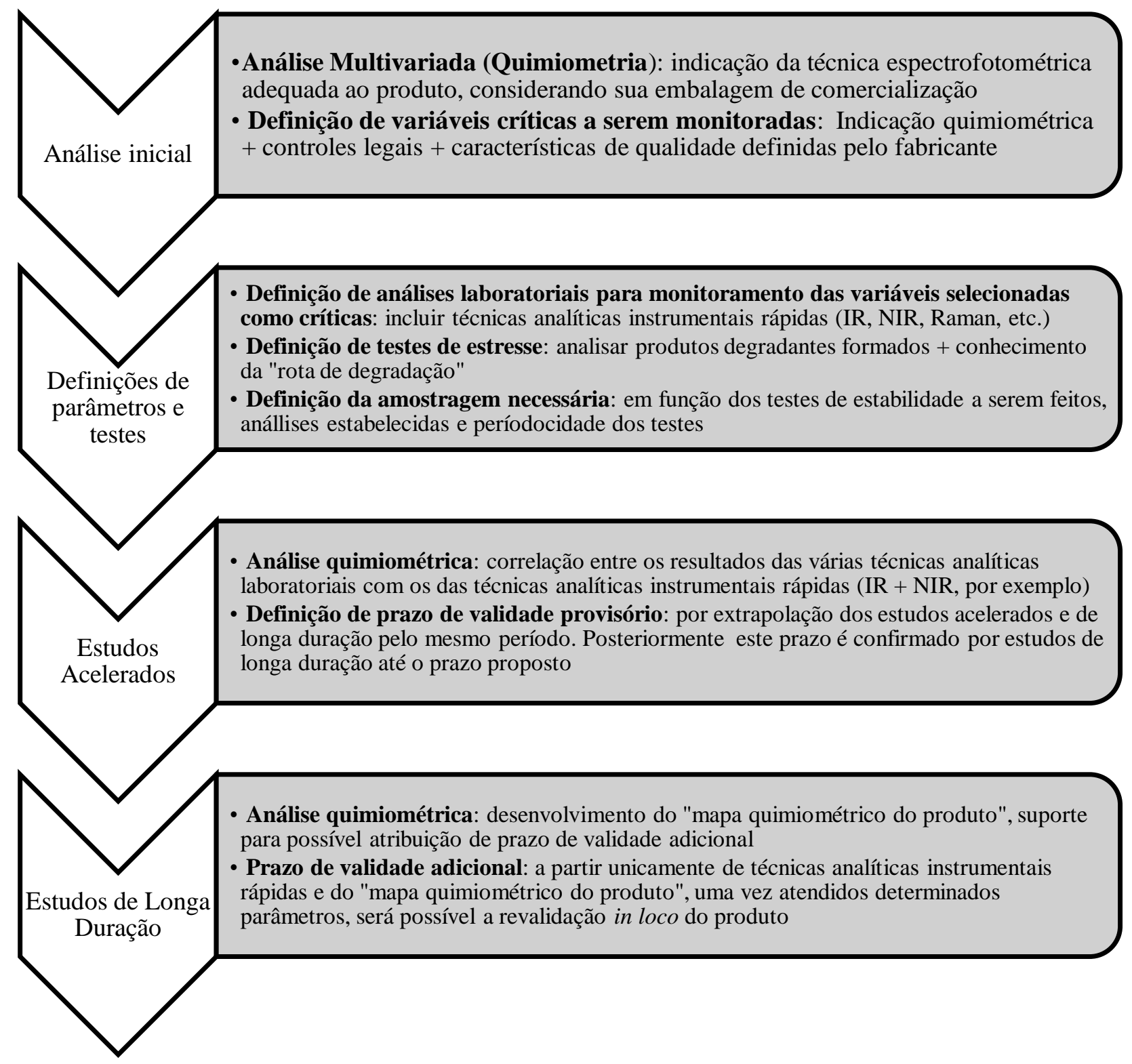

Figura 2 - Metodologia para revalidação de produtos químicos - ChemoMap

O mapa quimiométrico do produto, base da metodologia de revalidação ChemoMap, está sendo desenvolvido e testado, em bases de dados de três produtos direcionados ao mercado B2B, fornecidas pela empresa Oxiteno S.A., e de um produto, segmento de 
agronegócios, fornecida pela empresa Arysta LifeScience do Brasil Indústria Química e Agropecuária Ltda, direcionado ao mercado B2C.

Os mapas, uma vez concluídos, devem correlacionar, com confiabilidade determinada, resultados das técnicas instrumentais rápidas e de testes analíticos laboratoriais convencionais.

A partir do mapa quimiométrico, a análise de viabilidade de revalidação de um produto, se dará simplesmente pela leitura de seu espectro próximo à data de vencimento. Como as condições de armazenamento são determinantes na manutenção dos requisitos originais de qualidade, a viabilização do prazo adicional, só será possível para as embalagens de produtos cujos espectros forem avaliados.

\section{ABRANGÊNCIA}

Há uma vasta gama de categorias de produtos químicos no mercado.

A metodologia ChemoMap é aplicável a qualquer produto, desde que a análise multivariada inicial indique uma técnica espectrofotométrica compatível com o produto em análise. Caso não seja encontrada uma técnica que propicie leitura adequada dos espectros análise rápida responsiva -, a metodologia para revalidação através da leitura de espectros, ChemoMap, não será a indicada.

Já para atribuição simplesmente do prazo de validade, os parâmetros estabelecidos no guia de estabilidade para produtos químicos (Oriqui, Mori, Wongtschowski, 2014), e que levam em consideração o estado físico do produto - sólido, líquido, gasoso, etc. - e seu tipo de embalagem de comercialização, abrangem as mais diversas categorias.

\section{CONCLUSÃO}

A revalidação de produtos químicos, robusta em relação à segurança química e mantidos os padrões de qualidade originais pelo prazo adicional, é uma alternativa impactante em termos ambientais e de bem-estar público.

A revalidação de produtos, inclusive mais críticos que os químicos - medicamentos, por exemplo -, já é uma realidade no mercado internacional. O programa de extensão do prazo de validade de medicamentos, shelf-life extension program - SLEP, iniciado em 1986, pelo Departamento de Defesa dos Estados Unidos, DoD, juntamente com a agência reguladora Food and Drug Administration, FDA, e em vigor, considerou desde o princípio, sua 
funcionabilidade, os requisitos de rotulagem, os custos-benefícios, bem como sua fundamentação por meio de pesquisas científicas contundentes (Khan et al, 2014).

Analogamente e também respaldada por pesquisas e testes laboratoriais, o objetivo da metodologia ChemoMap é possibilitar às indústrias químicas uma alternativa sustentável em termos econômicos, ambientais e sociais, ao descarte prematuro de produtos teoricamente vencidos, mas ainda íntegros em seus requisitos de qualidade e de segurança.

A construção do mapa quimiométrico demanda um prazo médio de 30 meses de testes laboratoriais, que contemplam testes analíticos e estudos de estabilidade e espectrométricos em condições de estresse, acelerada e de longa duração. Em etapa anterior à qualificação de produtos para validação da aplicabilidade da metodologia ChemoMap, ou seja, determinação de técnica espectrofotométrica compatível, recomenda-se uma triagem para análise do impacto econômico, social e ambiental decorrente de suas possíveis revalidações.

Em 2015/2016 está prevista a publicação de um manual prático, com esclarecimentos passo a passo da metodologia, exemplificando-os com análises das bases de dados dos quatro produtos atualmente em estudo, sendo três deles direcionados ao mercado B2B e o último, ao mercado B2C.

\section{REFERÊNCIAS}

ANVISA, 2002 - Resolução RDC $\mathrm{N}^{0}$ 157, de 31 de maio de 2002. Disponível em http://www.diariodasleis.com.br/busca/exibelink.php?numlink=1-9-34-2002-05-31-157, $\quad$ e acessado em 20 de abril de 2014.

ANVISA, 2003 - Resolução RDC N $\mathrm{N}^{0}$ 210, de 04 de agosto de 2003. Disponível em http://www.diariodasleis.com.br/busca/exibelink.php?numlink=1-9-34-2003-08-04-210, e acessado em 07 de julho de 2014.

ANVISA, 2010 - Resolução RDC N ${ }^{0}$ 17, de 16 de abril de 2010 - Boas Práticas de Fabricação de $\quad$ Medicamentos. $\quad$ Disponível em http://bvsms.saude.gov.br/bvs/saudelegis/anvisa/2010/res0017_16_04_2010.html, e acessado em 20 de abril de 2014.

ANVISA, 2010 - Perguntas e Respostas sobre a Resolução - RDC nº17/2010, Boas Práticas de fabricação, $\quad$ Outubro $2010 . \quad$ Disponível em http://portal.anvisa.gov.br/wps/wcm/connect/6c2f9400474580df8ce2dc3fbc4c6735/Microsoft +Word+-+Perguntas+e+Respostas+RDC+17+Revis\%C3\% A3o+01+-+21-1010+enviada+\%C3\%A0+ASCOM.pdf?MOD=AJPERES, e acessado em 20 de abril de 2014. 
BRASIL, Decreto $\mathrm{N}^{\mathrm{o}}$ 8077, de 14 de agosto de 2013. Disponível em http://www.planalto.gov.br/ccivil_03/_Ato2011-2014/2013/Decreto/D8077.htm, e acessado em 07 de julho de 2014.

ANVISA, 2012 - Perguntas e Respostas sobre a Resolução - RDC n 48/2013, Boas Práticas de Fabricação para Produtos de Higiene Pessoal, Cosméticos e Perfumes, Abril 2012. Disponível

em

http://webcache.googleusercontent.com/search?q=cache:TGApGGDHqP8J:portal.anvisa.gov. br/wps/portal/anvisa/anvisa/transparencia/!ut/p/c4/04_SB8K8xLLM9MSSzPy8xBz9CP0os3h TQwNfRydDRwN_N2cjA08XVzOPUF-

PIGdvI_2CbEdFALBfe1Q!/\%3Furile\%3Dwcm\%253Apath\%253A/anvisa\%2Bportal/anvisa/t rasparencia/assunto\%2Bde\%2Binteresse/publicacoes\%2Btransparencia/faq\%2B-

\%2Bperguntas\%2Bfrequentes/cosmeticos\%2B-\%2Binformacoes $\% 2 \mathrm{Bgerais}+\& \mathrm{~cd}=1 \& \mathrm{hl}=\mathrm{pt}-$ $\underline{\mathrm{BR} \& \mathrm{ct}=\mathrm{clnk} \& \mathrm{gl}=\mathrm{br}}$, e acessado em 02 de julho de 2014.

ANVISA, 2013 - Resolução RDC N 47, de 25 de outubro de 2013. Disponível em http://www.anvisa.gov.br/medicamentos/bulas/rdc 47.pdf, acessado em 20 de abril de 2014.

ANVISA, 2013 - Resolução RDC $\mathrm{N}^{0}$ 48, de 25 de outubro de 2013. Disponível em http://www.cvs.saude.sp.gov.br/up/U_ANVISA-RDC-

48_251013\%20Cosm\%C3\%A9ticos.pdf, acessado em 20 de abril de 2014

BRASIL, Lei $\mathrm{N}^{\mathrm{o}}$ 6.360, de 23 de setembro de 1976. Disponível em http://www.planalto.gov.br/ccivil_03/leis/16360.htm, e acessada em 07 de julho de 2014.

BRASIL, Lei $\mathrm{N}^{\mathrm{o}}$ 6.437, de 20 de agosto de 1977. Disponível em http://www.planalto.gov.br/ccivil_03/leis/L6437.htm, e acessada em 07 de julho de 2014.

BRASIL, Lei $\mathrm{N}^{\mathrm{o}}$ 9.782, de 26 de janeiro de 1999. Disponível em http://www.planalto.gov.br/ccivil_03/leis/L9782.htm, e acessada em 07 de julho de 2014.

BRASIL, Lei $\mathrm{N}^{\mathrm{O}}$ 8.078, de 11 de setembro de 1990, Lei dos Direitos do Consumidor. Disponível em https://www.planalto.gov.br/ccivil_03/leis/18078.htm, e acessada em 20 de fevereiro de 2014.

DoD 4140.27-M/May, 5, 2003. $\quad$ Disponível em https://www.shelflife.hq.dla.mil/policy_DoD4140_27.aspx, e acessado em 07 de julho de 2014.

KHAN, S.R. et al (2014); United States Food and Drug Administration and Departments of Defense shelf-life extension program of pharmaceutical products: progress and promise, J. Pharm Sci, 2014 May; 103(5): 1331-1336

MS, 1997 - Portaria $\mathrm{N}^{0}$ 500/MS/SNVS, de 09 de outubro de 1997. Disponível em http://www.cff.org.br/userfiles/file/portarias/500.pdf, e acessado em 20 de abril de 2014. 
MPF, 2011 - Ministério Público Federal, $3^{\text {a }}$ Câmara de Coordenação e Revisão - Consumidor e Ordem Econômica, Informativo de 28/out/2011. Disponível em http://3ccr.pgr.mpf.mp.br/secretaria-executiva-1/revisao/consumidor/consumidortemas/Texto\%20no\%2011\%20-Conceito\%20de\%20consumidor.pdf, e acessado em 20 de abril de 2014.

ORIQUI, L.O.; MORI, M.: WONGTSCHOWSKI, P. (2014); Shelf Life para a Indústria Química - Guia de estabilidade e definição de prazos de validade para produtos químicos, Editora Campus-Elsevier, $141 \mathrm{pp}$.

TREVISAN, M.G.; POPPI, R.J. (2006); Química Analítica de Processos, Química Nova, Vol.29, $\mathrm{N}^{\mathrm{o}}$ 5, pp. 1065-1071

VARMUZA, K.; FILZMOSER, P. (2009), Introduction to Multivariate Statiscal Analysis in Chemometrics, CRC Press - Taylor \& Francis Group, 321 pp. 